\title{
ESTIMATION OF THE TRAFFIC ACCIDENTS COSTS IN SERBIA BY USING DOMINANT COSTS MODEL
}

\author{
Boris Antić ${ }^{1}$, Milan Vujanić ${ }^{2}$, Krsto Lipovac ${ }^{3}$, Dalibor Pešić ${ }^{4}$ \\ Faculty of Transport and Traffic Engineering, University of Belgrade, Vojvode Stepe 305, Belgrade, Serbia \\ E-mails: ${ }^{1}$ b.antic@sf.bg.ac.rs; ${ }^{2}$ m.vujanic@sf.bg.ac.rs; ${ }^{3}$ k.lipovac@sf.bg.ac.rs; \\ ${ }^{4}$ d.pesic@sf.bg.ac.rs (corresponding author)
}

Submitted 29 December 2010; accepted 12 April 2011

\begin{abstract}
This paper presents estimation of the traffic accident costs in Serbia, based on original dominant costs model. Dominant costs model uses human capital approach and this model is developed for simple and quick calculation of the traffic accidents costs, because other simple methods as 1 million rules, are not suitable for estimation of the traffic accident costs in the countries with a low GDP per capita. Knowing the costs of traffic accidents is of crucial importance for establishing traffic safety to the level defined by the size of costs made as a consequence of unsafely. So, politicians, decision makers and stakeholders in the field of traffic safety often need quick estimation of the traffic accident costs and economic effects of the particular measures which are applied for decreasing the number and severity of traffic accidents. The estimation of the level of the traffic accidents costs in Serbia, based on the official data (from the Ministry of Interior of the Republic of Serbia) about traffic accidents in Serbia for 2008 is shown in this paper and the comparison between predicted and calculated value of the traffic accident costs for 2009 is also presented.
\end{abstract}

Keywords: traffic accident costs, dominant costs model, human capital approach, costs compared to GDP, traffic safety.

\section{Introduction}

Bearing in mind that the influence of transportation, its systems and functioning is very important for national politics and economy and it is clear that special attention must be paid to the economic evaluation. Researches show that the influence of transportation is often underestimated in planning social and business costs, wherein you also have to keep in mind the influences of globalization, especially those connected with the removing of market limits and the liberalization of the market. Many researches have been dealing with the evaluation of the traffic accidents costs, with the concept of determination of traffic accidents costs (Andersson 2007; Schwab Christe, Soguel 1995; Blincoe et al. 2002; Alfaro et al. 1994), the comparison of the calculated costs with Gross national product per capita (Connelly, Supagan 2006; Kopits, Cropper 2005; Jacobs et al. 2000; Elvik 2000; Al-Masaeid et al. 1999) and the observation of the specific influences on the traffic accidents costs (Ayuso et al. 2010; Steimetz 2008).

During evaluation of the traffic accidents costs it is important to have in mind the following criteria: the data should not be too old, all traffic accidents should be included (even those traffic accidents with Property damage), both the direct and indirect traffic accidents costs should be covered, and the costs should be shown in comparison with GDP (Elvik 2000).

The typology shown in Fig. 1 presents different methods for estimating traffic accident costs, developed by the Commission of the European Communities in project known as COST-313 (Alfaro et al. 1994). The costs of restitution are the direct costs generated by road accidents (medical costs, property damage, administrative costs etc.). Human capital approach is used to estimate the value of lost productive capacity due to the traffic death and the willingness-to-pay (WTP) ap-

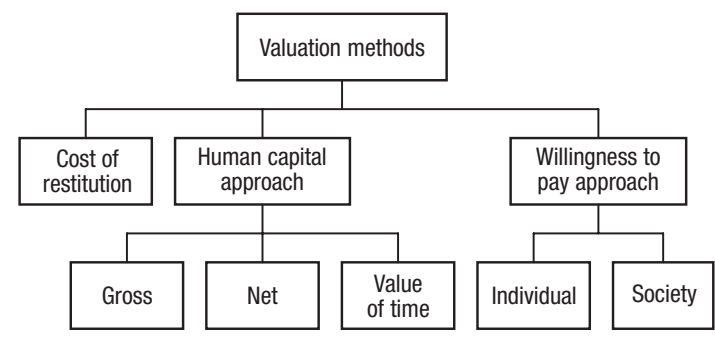

Fig. 1. Methods for estimating the traffic accident costs (Alfaro et al. 1994) 
proach is used to estimate the value of the lost quality of life. The individual WTP approach uses information obtained from individuals, while society WTP approach considers reduced risk from the implicit valuation in public decisions.

Fig. 2 shows the flow diagram of the Model used for estimation of the traffic accident costs in India (Valli, Sarkar 1997), but it is also used for prediction model using systems dynamic approach (Partheeban et al. 2008). The top of this diagram shows subsystem of the human accident cost and bottom of this diagram presents the vehicle damage cost subsystem, so the middle part shows the total cost subsystem.

Richardson (1997) for valuating the costs of injuries estimates the risk based on Potential Years of Life Lost (PYLL) or Disability adjusted Life Years (DALYs), while Brooks (1991) use method of Health Indices based on probability for longer and more qualitative life. For example, three years with a quality level value of 0.67 are equal to two years of life with a quality level 1 . The Method Cost of Illness is often used for estimating the material costs (Persson 1992), whereby economic costs of injury are allocated in two categories: direct costs (for prevention, detection, treatment, rehabilitation etc.) and

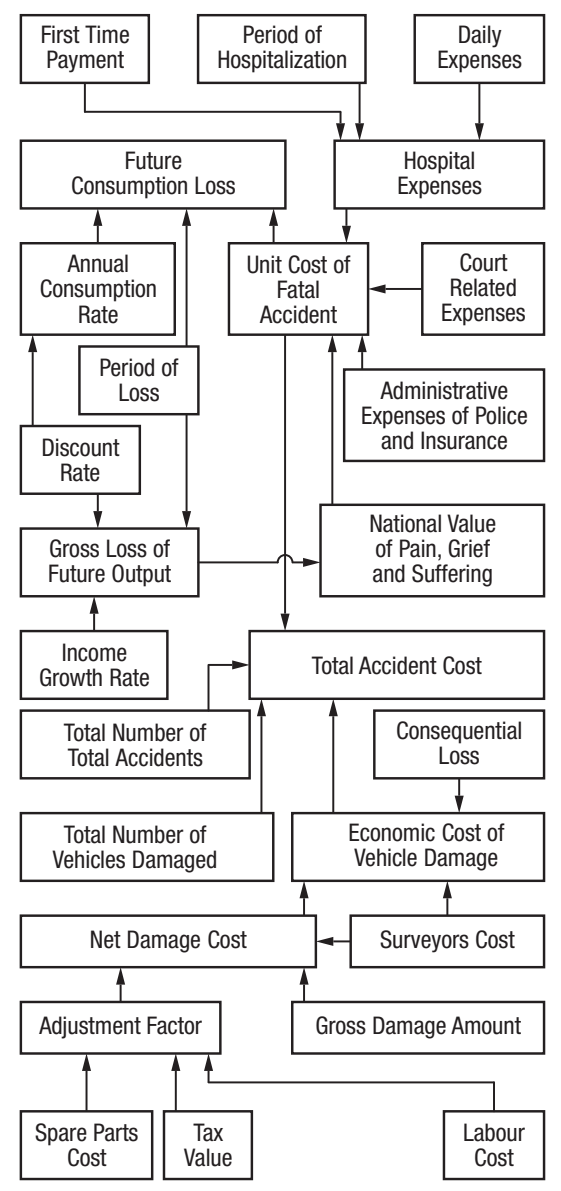

Fig. 2. Accident cost model - flow diagram (Valli, Sarkar 1997; Partheeban et al. 2008) indirect costs (value of goods or services which could be produced or done, in case that one was not injured).

Swedish National Road Administration for estimating the Traffic accident costs use Value of Statistical Life (VOSL) based on WTP approach. VOSL presents product of multiplying marginal value of WTP and inverse value of risk decreasing. For example, if each of 100.000 people are going to pay $10 €$ for decreasing probability of death for 1:100000, then total value for increasing the level of the traffic safety (VOSL) is 1 million $€$ (De Blaeij et al. 2000).

Taking into account the traffic accident costs in EU (45 billion ECU) and 45000 fatalities in EU, European Conference of Ministers of Transport (ECMT-CEMT) in 1997 introduced method - 'One million ECU test'. This simple method explains economic benefits to society of the avoidance of one death in traffic and provides a useful starting point for developing road safety policies. When EURO replaced ECU, European Conference of Ministers of Transport (ECMT-CEMT) introduced 1 million $€$ rule in its Road Safety Programme, and this estimation is still in use (Social and Economic Consequences... 2007).

De Blaeij et al. (2004), Sælensminde (2001) in Fig. 3 shows official monetary valuation of road accident death in some European countries, and these valuations vary very emphatically. Fig. 3 shows two important facts. First, values highly depend on the method used for estimating these costs. So, values based on the WTP approach are twice as high as values on other approaches. Second importance is the level of real income in the country, because lower values are found in countries with lower GDP per capita.

According to low GDP per capita in Serbia, previous discussion explains why 1 million $€$ rule is not suitable for estimating the traffic accident costs in Serbia. Particularly, if 1 million $€$ rule is applied in Serbia, then total traffic accident costs will be overestimated and it was necessary to create a simple model for quick, but sufficiently accurate estimation of the traffic accident costs, which could be useful for politicians and decision makers in a field of traffic safety.

Therefore, authors developed original 'Dominant costs model' for calculation of the market costs of traffic accidents, which are considered in human capital method.

Total costs of the traffic accidents are obtained as a sum of the market costs value which is calculated by using 'dominant costs model' and humane costs value which is estimated according to recommended relations between humane and market traffic accidents costs for certain type of the traffic accident.

In contrast to the other models, calculation of the traffic accident costs by using 'dominant costs model' is quick and simple, and all necessary data for calculations are easily available, so additional complicated polls and surveys for the collection of data are not needed. 


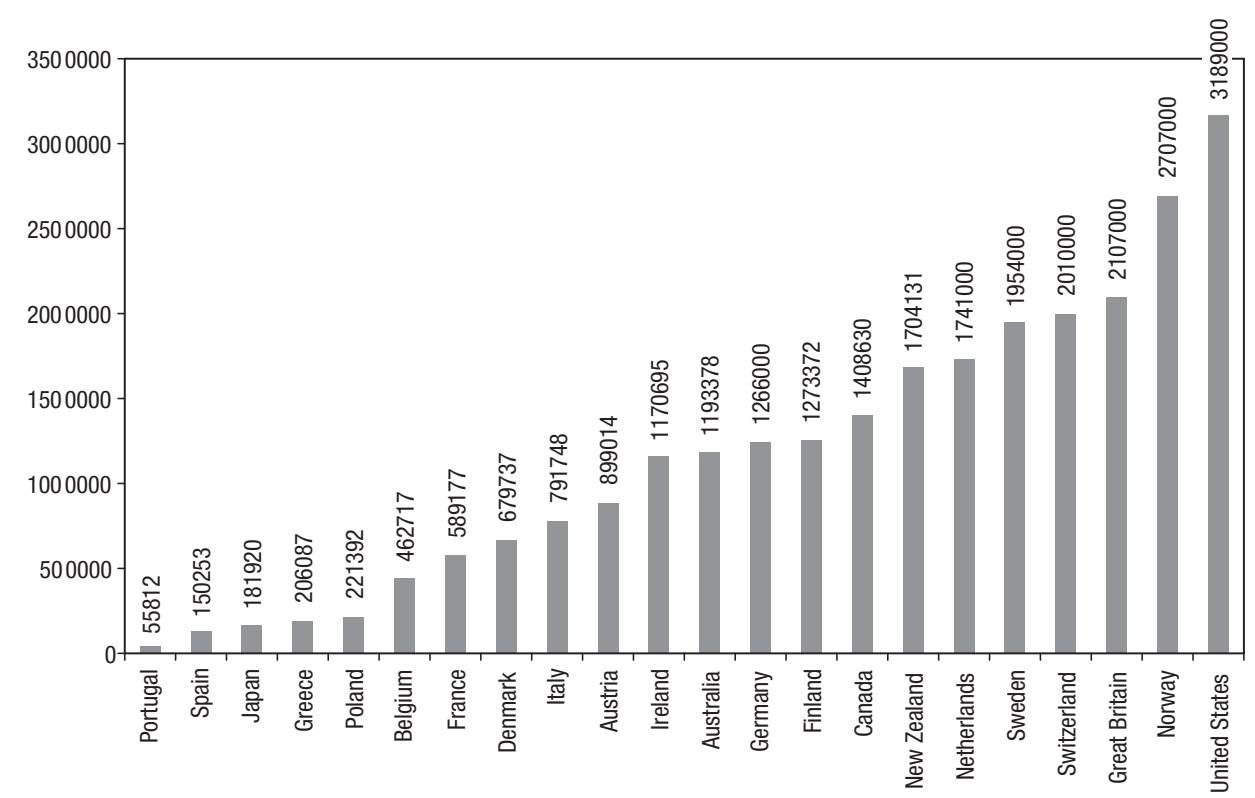

Fig. 3. Official monetary valuation of a road accident death in selected countries ( $€$ in 2002 prices) (De Blaeij et al. 2004; Saelensminde 2001)

\section{Methods}

The analysis of researches connected with the traffic accidents costs evaluation around the world indicates several costs categories which include almost all costs and losses made as a consequence of traffic accidents. Still, the participation of certain categories of costs in the final 'price' of a traffic accident varies both among accidents of the same type, that is accidents with the same consequences (for example accidents with a fatal outcome) and especially among accidents with different kinds of consequences (for example, between property damage only accidents (PDO) and accidents with seriously injured (SEI)).

Due to the specific structure of costs of certain traffic accidents categories, the percentage of some costs categories in costs structure is more or less negligible compared to some other costs categories that dominate the costs structure. Therefore, these costs are called the dominant costs.

Having that in mind, conclusion is that by applying the dominant costs model, value of a certain type of a traffic accident is estimated by knowing one, two or mostly three categories of costs caused by traffic accidents. For the need of this model, traffic accidents are classified by its consequences to: property damage accidents (PDO), traffic accidents with (slight) injured (SLI), traffic accidents with seriously injured (SEI) and traffic accidents with fatal outcome (FATAL). Costs categories that can be found in the human capital method are also considered and they are:

- Medical costs (MC) - which cover all the costs of a medical care for the injuries caused by a traffic accident, including ambulance transport. Beside that, medical costs also include the costs of the emergency room, hospital bills, home visits, physical therapy, rehabilitation, medicines, prosthetic devices etc.
- Emergency services cost (ESC) - which include police, fire department and towing service costs.

- Lost productivity (LP) - which includes the costs of lost market productivity and a household productivity. Market productivity represents the discount value of a lost income during the remaining years of life, whereas household productivity represents the value of the diminished household activities, defined as a 'price' of hiring a person responsible for the implementation of those activities.

- Insurance administration (IA) - which includes insurance companies' costs caused by paying the compensation to the insurants who participated in the accident and the costs of defense attorneys.

- Workplace costs (WPC) - which include the costs caused by working process failure due to the absence or total lost of a worker. They also include the costs caused by hiring and 'training' a new employee, overtime work so that the losses caused by the absence of a worker could be compensated, and the administrative costs caused by the change of staff.

- Legal costs (LC) - represent the costs of a judicial system in the processes that come as a consequence of traffic accidents.

- Travel Delay (TD) - represents the value of travel delay for persons that did not participate in the accident but were kept because of the accident.

- Property damage (PD) - includes the costs of vehicles, goods, equipment and road objects damages and other things, caused by the accident.

Traffic accidents costs per consequences, obtained using this dominant costs model, include only the costs categories mentioned above, meaning that the result of this model represents the average value of market costs of traffic accidents. It does not consider the costs of suf- 
fering, pain and the diminished quality of life, which will be considered afterwards.

Market costs of traffic accidents by using 'Dominant costs model' are calculated using the form:

$$
\begin{aligned}
& T A C=N_{P D O} \cdot \frac{P D}{d_{P D O}}+ \\
& N_{S L I} \cdot \frac{P D+n_{S L I} \cdot\left(M C_{S L I}+L P_{S L I}\right)}{d_{S L I}}+ \\
& N_{S E I} \cdot \frac{n_{S E I} \cdot\left(M C_{S E I}+L P_{S E I}\right)}{d_{S E I}}+ \\
& N_{F A T} \cdot \frac{n_{F A T} \cdot L P_{F A T}}{d_{F A T}},
\end{aligned}
$$

where: $N_{i}$ represents number of the certain type of traffic accidents (PDO - property damage only, SLI - traffic accidents with slightly injured; SEI - traffic accidents with seriously injured; FAT - traffic accident with fatal outcome.

\subsection{The Parameters of a Dominant Costs Model for Property Damage in Traffic Accidents Only}

Traffic accidents with property damage only (PDO) are most widespread type of traffic accidents, especially when you know that high number of these accidents is not reported to the police. The analysis of PDO traffic accidents costs shows that property damage costs dominate the structure with about $60 \%$, followed by the travel delay costs with about $30 \%$ (Blincoe et al. 2002). Other components or types of costs like emergency services costs or insurance administration costs are significantly less represented with less than $4 \%$ (Fig. 4).

Bearing in mind these facts and the PDO accidents, it is clear that property damage costs are the basic element for the evaluation of costs for this type of accidents. It should be mentioned that the evaluation of total costs for accidents with property damage would be even more precise if the travel delay costs were included, but the evaluation of travel delay costs is extremely complicated because it depends on numerous factors and complicates the evaluation of costs. Taking into consideration and by applying the dominant costs model, average PDO traffic accident costs can be obtained by busing the form:

$$
C_{P D O}=\frac{P D}{d_{P D O}}
$$

where: $P D$ - represents property damage costs per one accident; $d_{P D O}$ - represents the level of dominant costs of the traffic accidents with property damage (according to the structure of costs for this type of accidents the level of domination is 0.6 ).

\subsection{The Parameters of Dominant Costs Model for Traffic Accidents with (Slightly) Injured}

The specificities of traffic accidents with (slightly) injured show that property damage costs with $41 \%$, medical costs with $19 \%$ and lost productivity with $20 \%$ dominates the structure of costs of these accidents. These three mentioned categories participate with $80 \%$ in the costs structure per one slight injured participant (Blin- coe et al. 2002), whereas other categories of costs are individually represented with no more than 7\% (Fig. 5).

Considering that, the calculation of average traffic accident with (slightly) injured costs, using the dominant costs model, is based on evaluation of the costs of property damage, medical costs and lost productivity costs, the average traffic accident with (slightly) injured costs could be obtained using the form:

$$
C_{S L I}=\frac{P D+n_{S L I} \cdot\left(M C_{S L I}+L P_{S L I}\right)}{d_{S L I}},
$$

where: $P D$ - represents property damage costs per one accident; $n_{S L I}$ - the number of the slightly injured per accident; $M C_{S L I}$ - medical costs per one slightly injured person; $L P_{S L I}$ - lost productivity costs per one slightly injured person; $d_{S L I}$ - the level of dominant costs of the traffic accidents with slightly injured (according to the structure of costs for this type of accidents the level of domination is 0.8 ).

\subsection{The Parameters of Dominant Costs Model for Traffic Accidents with Seriously Injured}

Traffic accidents with seriously injured leave behind the largest consequences bearing in mind the market costs of traffic accidents (Fig. 6), so it is not hard to conclude

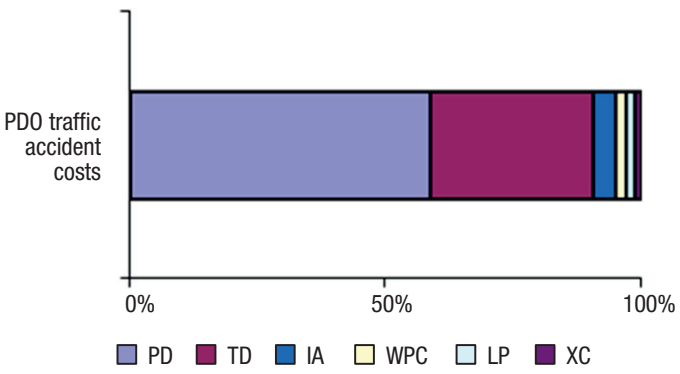

Fig. 4. The structure of PDO traffic accidents costs (Blincoe et al. 2002)

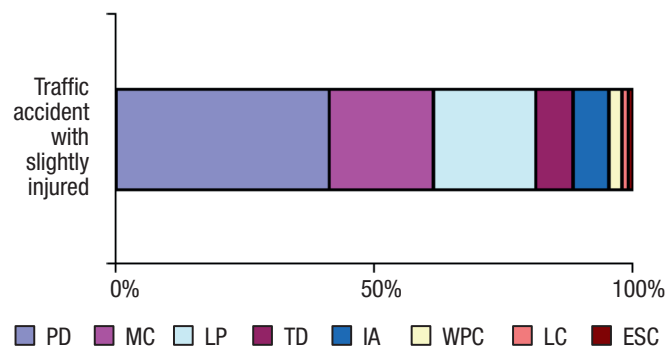

Fig. 5. The structure of costs for the traffic accidents with (slightly) injured (Blincoe et al. 2002)

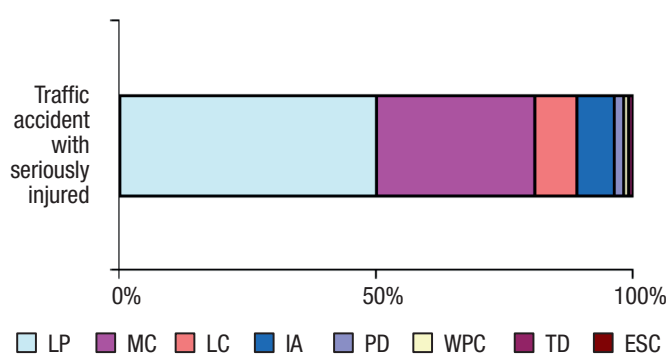

Fig. 6. The structure of costs for traffic accidents with seriously injured (Blincoe et al. 2002) 
that considering the features of these accidents, lost productivity costs (50\%) and medical costs (30\%) dominate the costs structure with $80 \%$ (Blincoe et al. 2002).

Having this in mind, average traffic accidents with seriously injured costs, using the dominant costs model, could be calculated using the form:

$$
C_{S E I}=\frac{n_{S E I} \cdot\left(M C_{S E I}+L P_{S E I}\right)}{d_{S E I}},
$$

where: $n_{S E I}$ - represents the number of seriously injured people per accident; $M C_{S E I}-$ medical costs per one seriously injured person; $L P_{S E I}$ - lost productivity costs per one seriously injured person; $d_{S E I}$ - the level of dominant costs of the traffic accidents with seriously injured (according to the structure of costs for this type of accidents the level of domination is 0.8 ).

\subsection{The Parameters of Dominant Costs Model for Fatal Traffic Accidents}

Observing the costs structure of traffic accidents with a fatal outcome (Fig. 7), it can be noticed that lost productivity costs dominate the costs structure with $80 \%$.

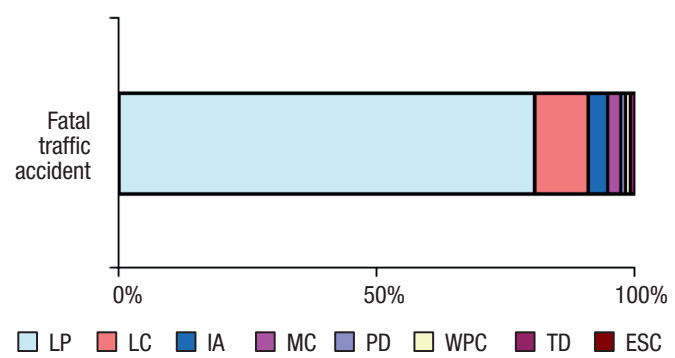

Fig. 7. The structure of costs for traffic accidents with fatal outcome (Blincoe et al. 2002)

Average traffic accident with fatal outcome costs can be determined using the form:

$$
C_{F A T}=\frac{n_{F A T} \cdot L P_{F A T}}{d_{F A T}},
$$

where: $n_{F A T}-$ represents the number of fatalities; $L P$ $F A T^{-}$lost productivity costs per one dead person; $d_{F A T}-$ the level of dominant costs of the fatal traffic accidents (according to the structure of costs for this type of accidents the level of domination is 0.8 ).

\section{Results}

\subsection{Determining Average Market Costs of a Traffic Accident in the Republic of Serbia}

Taking into account that about $10 \%$ of vehicles with 'casco' insurance participate in traffic accidents, and that the average paid damage per one vehicle with 'casco' insurance that participated in an accident for the year 2003 is $603 €$ (data taken from: the Yearly statistic review of people and property insurance for 2000 and 2001, Association of insurance companies of Yugoslavia; information for 2002 and 2003 - Insurance company DDOR Novi Sad, Serbia, http://www.ddor.rs), and that Property damage for the rest $90 \%$ of vehicles is defined as half the value of a Property damage for the vehicles with 'casco' insurance (302 $€)$, the average amount of property damage per vehicle would be $332 €$, and average property damage per accident $558 €$. Applying these values to the form (1) and taking into account the average number of vehicles involved in traffic accidents (1.76 according traffic accidents data - Ministry of Interior of the Republic of Serbia, http://www.mup.rs), average PDO traffic accident in the Republic of Serbia would be $980 €$ at the level of the year 2003 which was taken as a basic year for the calculations.

For determining the costs of a traffic accident with injured it is necessary to evaluate medical costs and lost productivity costs. Taking into account the price of a day in a hospital, that is $75 €$ (data taken from MEDICUS clinic, Belgrade, Serbia) and average time of hospital care per one injured person, which is two days, the calculated price of medical costs per one injured is $150 €$.

Bearing in mind the average earnings in the Republic of Serbia and the period of lost income that is five days (Guidelines for Estimating... 2003), lost productivity costs are determined as $65 €$, so the average costs of traffic accident with (slightly) injured at the level of the year 2003 would be $1103 €$, whereas the average costs per one slightly injured person would be $805 €$ and average number of 1.37 injured persons per accident.

Taking into account the costs of traffic accidents with seriously injured, the amount of medical costs, determined by the price of one hospital day which is $75 €$ and the number of hospital days predicted for a seriously injured person (30 days), would be $2250 €$. Lost productivity costs, considering the number of lost days per one injured (57 days, of which 30 are hospital days and 27 days of recovery), lost days for a caregiver (8 days) and the average daily gross earning of the injured and a caregiver, would be $845 €$ per one seriously injured person. According to this, average costs of traffic accidents with seriously injured in the Republic of Serbia at the level of the year 2003 would be $5300 €$, whereas average costs per one seriously injured person would be $3869 €$ average number of 1.37 injured persons per accident.

For determining average costs of a traffic accident with fatal outcome, it is necessary to determine the worth of a lost productivity which this person would have made if there had not been the tragic outcome of the accident. Beside the average yearly gross earning, it is also necessary to determine the average number of lost productivity years per one death, which can be determined based on the average age of the death and life expectancy. Bearing in mind that in the Republic of Serbia average life expectancy is 73 years (Statistics Institute of Serbia, http://www.rzs.rs.ba), and that the average age of the persons who died in traffic accidents during 2003 was 47 years (data taken from the Ministry of Interior of the Republic of Serbia, http://www.mup.rs), it is clear that lost productivity of the dead should be calculated for the period of 26 years. Considering the average yearly personal income in the Republic of Serbia (3276€) and opportunity capital price of $10 \%$, that is, the discount rate of 0.1 , lost productivity income per person at the level of the year 2003 would be $33287 €$. Applying 
the dominant costs model, or involving the data about the lost productivity costs per person and the average number of death per accident into the form (4), average costs of a traffic accident with fatal outcome in the Republic of Serbia at the level of the year 2003 would be $45770 €$, and average costs per one dead $41609 €$ (average number of deaths per fatal accident is 1.1).

The costs of traffic accidents in Serbia are shown in Table 1, according to $78.2 \%$ increase of prices and life costs in Serbia during the period 2003-2008 (Statistics Institute of Serbia, http://www.rzs.rs.ba).

Table 1. The unit market costs of traffic accidents in the Republic of Serbia for 2003, 2008 and 2009 given in $€$

\begin{tabular}{cccccccc}
\hline & \multicolumn{3}{c}{ COST PER ACCIDENT } & \multicolumn{3}{c}{ COST PER PERSON } \\
\cline { 2 - 8 } & PDO & SLI & SEI & FATAL & SLI & SEI & FATAL \\
\hline 2003 & 980 & 1103 & 5300 & 45770 & 805 & 3869 & 41609 \\
\hline 2008 & 1747 & 1966 & 9445 & 81562 & 1435 & 6895 & 74147 \\
\hline 2009 & 1929 & 2170 & 10427 & 90044 & 1584 & 7612 & 81858 \\
\hline
\end{tabular}

Nevertheless, there is a factor that cannot be calculated and used in determining the total traffic accidents costs, and that is economic quantification of the pain and suffering, in researches simply called 'lost quality of life' costs or human costs. Numerous researches considering the relations between humane and market traffic accident costs, show great differences in the evaluation of humane costs, depending on the type of the accident, the period when the research was made and the applied method, the difference range which presents humane costs expressed as a part of market costs is from about $4 \%$ in Belgium, $71 \%$ in Great Britain, and even 244\% in the USA. Taking into account the recommendations for evaluation of traffic accidents costs in the developing countries given by the Department for international development - DFID, and in order to include these, so called, human costs in the price of a traffic accident, enlargement of the market costs by the types of traffic accidents with the correction factors is recommended (Guidelines for Estimating... 2003).

The researches (Jacobs et al. 2000), showed that factors recommended by the TRL laboratory in 1995 (1.2 - for traffic accident with fatal outcome, 1.5 - for traffic accident with permanent disability, 1.3 - for traffic accident with seriously injured and 1.01 - for traffic accident with injured) were corrected and new ones were suggested: 1.28 - for traffic accident with fatal outcome, 1.5 - for traffic accident with seriously injured, 1.08 for traffic accident with injured (Guidelines for Estimating... 2003).

By applying experiences from the USA (Blincoe et al. 2002) about the relations between humane and market traffic accidents costs, and also considering the values of average traffic accidents market costs in the Republic of Serbia, the total traffic accidents costs in the Republic of Serbia for the year 2003 and 2008 were evaluated and shown in details in Table 2.

\subsection{The Problem of Unreported Traffic Accidents}

According to World Health Organization (WHO, http:// www.who.int/en) data from 1998, the number of the dead in road crashes over the world is estimated to about 1.17 million, and is almost two times larger than 550000, which is the number of the dead officially recorded in statistic data. This information is more than enough to show that the problem of non-reported traffic accidents is very common round the world. Besides, there is no unique, harmonized and standardized method that could be used to determine precisely the number of these accidents and then to determine the level of costs made as a consequence of traffic accidents. It is important to mention that non-reported traffic accidents do not cause all the costs which are a common part of the reported ones, therefore the costs of these accidents are less. Bearing in mind these data, the costs of unreported traffic accidents in the Republic of Serbia at the lowest level are determined using the following assumptions:

- the number of traffic accidents with property damage which are not reported is estimated to $75 \%$ of the reported traffic accidents;

- the number of unreported injured people is estimated to $50 \%$ of the reported ones;

- the number of unreported seriously injured people is estimated to $5 \%$ of the reported ones;

- it is assumed that in Serbia all fatal traffic accidents are recorded in the official statistics.

Taking into account these assumptions, the number of non-reported traffic accidents with property damage in the Republic of Serbia, and the number of the injured and the dead for 2003 and for 2008 is shown in Table 3.

Table 2. Average, humane and total costs in the Republic of Serbia for 2003, 2008 and 2009 given in $€$

\begin{tabular}{|c|c|c|c|c|c|c|c|}
\hline & \multicolumn{4}{|c|}{ COST PER ACCIDENT } & \multicolumn{3}{|c|}{ COST PER PERSON } \\
\hline & PDO & SLI & SEI & FATAL & SLI & SEI & FATAL \\
\hline UNIT & 980 & 1103 & 5300 & 45770 & 805 & 3869 & 41609 \\
\hline HUMAN/UNIT & 0 & 0.42 & 1.09 & 2.44 & 0.42 & 1.09 & 2.44 \\
\hline HUMAN & 0 & 463 & 5777 & 111679 & 338 & 4217 & 101526 \\
\hline TOTAL (2003) & 980 & 1566 & 11077 & 157449 & 1143 & 8086 & 143135 \\
\hline TOTAL (2008) & 1747 & 2791 & 19739 & 280574 & 2043 & 14417 & 255210 \\
\hline TOTAL (2009) & 1929 & 3082 & 21793 & 309753 & 2250 & 15909 & 281593 \\
\hline
\end{tabular}


Table 3. Reported and unreported consequences of traffic accidents for 2003, 2008 and 2009

\begin{tabular}{clcccc}
\hline \multirow{2}{*}{2003} & PDO & SLI & SEI & FATAL \\
\cline { 2 - 6 } & REPORTED $^{*}$ & 43245 & 11403 & 4550 & 868 \\
\cline { 2 - 6 } & UNREPORTED $^{2}$ & 32434 & 5702 & 228 & - \\
\hline \multirow{2}{*}{2008} & TOTAL & 75679 & 17105 & 4778 & 868 \\
\cline { 2 - 6 } & REPORTED $^{*}$ & 51057 & 17080 & 5195 & 897 \\
\cline { 2 - 6 } & UNRPORTED $^{2}$ & 38293 & 8540 & 260 & - \\
\hline \multirow{2}{*}{2009} & TOTAL $^{*}$ & 89350 & 25620 & 5455 & 897 \\
\cline { 2 - 6 } & UNPORTED $^{*}$ & 49070 & 16521 & 4991 & 808 \\
\cline { 2 - 6 } & TOTAL & 36803 & 8261 & 250 & - \\
\hline \multirow{2}{*}{ TNORTED } & 85873 & 24782 & 5241 & 808 \\
\hline
\end{tabular}

${ }^{\star}$ Source: Ministry of Interior of the Republic of Serbia, http://www.mup.rs

Costs made as a consequence of traffic accidents in Serbia, based on average costs and dominant costs model, for the year 2003 are about 257 million $€$, and for 2008 about 516 million $€$ (Table 4). Comparing traffic accidents costs and the number of the dead, average traffic accidents costs in Serbia for the year 2003 per one dead are about $295000 €$, and for the year 2008 about $575000 €$.

For the purpose of seeing the forecasting capabilities of the dominant costs model, traffic accident costs for each year during the period 2003-2008 are calculated, according to the number of the traffic accidents taken from the Ministry of Interior of the Republic of Serbia (http://www.mup.rs), and also according to the increasing value of the prices and life costs in Serbia during the period between 2003-2008. In considered period, traffic accident costs show increasing linear trend (Fig. 8), with $R^{2}$ value of 0.984 . Having in mind this linear trend, forecasted value of the traffic accident costs in Serbia for the 2009 is about 567 million $€$.

Taking into account the number of the traffic accidents in Serbia in 2009, previously explained assumptions for unreported traffic accidents and $10.4 \%$ higher prices and life costs in Serbia in 2009 to 2008, calculated traffic accident costs in Serbia are about 532 million $€$. Comparison between predicted and calculated value of the traffic accident costs for 2009, shows that calculated value is only $6 \%$ lower than predicted value, so that dominant costs model could be also successfully used for forecasting of the traffic accident costs.

\section{Discussion and Conclusion}

1. Having in mind the transition period that Serbia is in, the models for 'quick' traffic accidents costs evaluation, developed in countries with significantly higher gross national product, unfortunately cannot be applied correctly in our conditions. Taking this into account, it was necessary to develop a procedure that would use more or less simple calculation and determine traffic accidents costs in Serbia.

2. The conducted researches, using the developed dominant costs model, showed that traffic accidents costs per one dead in Serbia for the year 2003 are about 257 million $€$, and in 2008 the amount of 516 million $€$ was reached. Average traffic accidents costs in Serbia for 2003 per one dead are about $295000 €$, and for 2008 about $575000 €$.

3. According to the estimations of GDP per capita for the year 2003 (World Development Indicators Data-

Table 4. Total traffic accidents costs in Serbia for 2003, 2008 and 2009 given in $€$

\begin{tabular}{lccccc}
\hline & PDO & SLI & SEI & FATAL & TOTAL \\
\hline TOTAL COSTS $(2003)$ & 74165175 & 19550444 & 38630866 & 124241180 & 256587665 \\
\hline TOTAL COSTS $(2008)$ & 156094450 & 52213360 & 78644735 & 228923370 & 515875915 \\
\hline TOTAL COSTS $(2009)$ & 165621260 & 55748978 & 83373205 & 227526749 & 532270192 \\
\hline
\end{tabular}

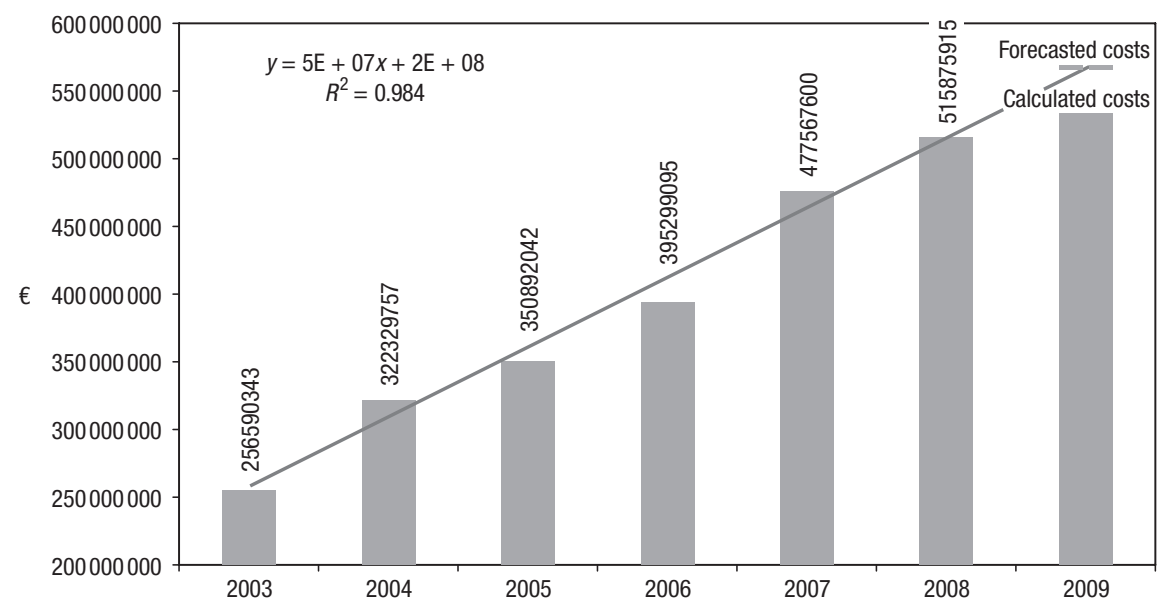

Fig. 8. Traffic accidents costs in Serbia during the period 2003-2008 with forecasted and calculated value for 2009 
base, World Bank, http://data.worldbank.org/indicator) of 2337 US \$, traffic accidents costs in Serbia, observed as a part of GDP are about $1.6 \%$, whereas bearing in mind the data for 2008, according to which GDP per capita in Serbia is 6812 US \$ (World Development Indicators Database, World Bank, http:// data.worldbank.org/indicator), traffic accidents costs in 2008 are $1.4 \%$ of GDP, that corresponds to the researches (Jacobs et al. 2000) which say that the size of traffic accidents costs in the countries which are in transition is about $1.5 \%$ of GDP. This proves that the estimation of the traffic accident costs in Serbia by using 'Dominant costs model' is sufficiently accurate and could be successfully used.

4. Taking into account the number of the traffic accidents and increasing value of the prices and life costs in Serbia during the period 2003-2008, traffic accident costs shows increasing linear trend with $R^{2}$ value of 0.984 . Having in mind this linear trend, forecasted value of the traffic accident costs in Serbia for the 2009 is about 567 million $€$. Calculated traffic accident costs in Serbia in 2009 by using 'Dominant costs model' are about 532 million $€$, which is only $6 \%$ lower than predicted value, so 'Dominant costs model' is also useful for forecasting the traffic accident costs.

5. Now, that all traffic accidents costs in Serbia are evaluated, the problem of determining economic losses made due to traffic accidents caused by a concrete problem, is significantly simplified, so by establishing the relationship between invested economic funds for solving that concrete problem and the size of economic losses caused by the problem, it is possible to determine the economic benefits achieved after implementing certain measures in order to improve traffic safety level. This way, a significant contribution to traffic safety management is made because it is possible to direct an intensive action towards the measures which provide the largest economic benefits.

\section{References}

Alfaro, J.-L.; Chapuis, M.; Fabre, F. 1994. Socioeconomic Cost of Road Accidents. COST 313. Report EUR 15464 EN. Commission of the European Communities, Brussels. 127 p.

Al-Masaeid, H. R.; Al-Mashakbeh, A. A.; Qudah, A. M. 1999. Economic costs of traffic accidents in Jordan, Accident Analysis and Prevention 31(4): 347-357. doi:10.1016/S0001-4575(98)00068-2

Andersson, H. 2007. Willingness to pay for road safety and estimates of the risk of death: evidence from a Swedish contingent valuation study, Accident Analysis and Prevention 39(4): 853-865. doi:10.1016/j.aap.2006.12.008

Ayuso, M.; Guillén, M.; Alcañiz, M. 2010. The impact of traffic violations on the estimated cost of traffic accidents with victims, Accident Analysis and Prevention 42(2): 709-717. doi:10.1016/j.aap.2009.10.020

Blincoe, L.; Seay, A.; Zaloshnja, E.; Miller, T.; Romano, E.; Luchter, S.; Spicer, R. 2002. The Economic Impact of Motor Vehicle Crashes 2000. NHTSA Technical Report DOT HS 809 446. U.S. Department of Transportation. 86 p. Available from Internet: <http://www.nhtsa.gov/DOT/NHTSA/ Communication\%20\&\%20Consumer\%20Information/Articles/Associated\%20Files/EconomicImpact2000.pdf>.
Brooks, R. G. 1991. Health Status and Quality of Life Measurement: Issues and Developments. The Swedish Institute for Health Economics, Lund. 94 p.

Connelly, L. B.; Supangan, R. 2006. The economic costs of road traffic crashes: Australia, states and territories, Accident Analysis and Prevention 38(6): 1087-1093. doi:10.1016/j.aap.2006.04.015

De Blaeij, A. T.; Florax, R. J. G. M.; Rietveld, P.; Verhoef, E. 2003. The value of statistical life in road safety: a metaanalysis, Accident Analysis and Prevention 35(6): 973-986. doi:10.1016/S0001-4575(02)00105-7

De Blaeij, A.; Koetse, M.; Tseng, Y.-Y.; Rietveld, P.; Verhoef, E. 2004. Valuation of Safety, Time, Air Pollution, Climate Change and Noise; Methods and Estimates for Various Countries. Report prepared for ROSEBUD (Road Safety and Environmental Benefit-Cost and Cost-Effectiveness Analysis for Use in Decision-Making). Department of Spatial Economics, Vrije Universiteit, Amsterdam.

Elvik, R. 2000. How much do road accidents cost the national economy?, Accident Analysis and Prevention 32(6): 849851. doi:10.1016/S0001-4575(00)00015-4

Guidelines for Estimating the Costs of Road Crashes in Developing Countries. 2003. Department for International Development Project R7780: Final Report. 49 p. Available from Internet: <http://www.transport-links.org/transport_links/ filearea/publications/1_807_R\%207780.PDF>.

Jacobs, G.; Aeron-Thomas, A.; Astrop, A. 2000. Estimating global road fatalities, TRL Report 445.36 p. Available from Internet: <http://www.transport-links.org/transport_links/ filearea/publications/1_329_TRL445.pdf>.

Kopits, E.; Cropper, M. 2005. Traffic fatalities and economic growth, Accident Analysis and Prevention 37(1): 169-178. doi:10.1016/j.aap.2004.04.006

Partheeban, P.; Arunbabu, E.; Hemamalini, R. R. 2008. Road accident cost prediction model using systems dynamics approach, Transport 23(1): 59-66. doi:10.3846/1648-4142.2008.23.59-66

Persson, U. 1992. Three Economic Approaches to Valuing Benefits of Traffic Safety Measures. The Swedish Institute for Health Economics, Lund. 59 p.

Richardson, H. A. 1997. Motor Vehicle Traffic Crashes as a Leading Cause of Death in the U.S., 1992. NHTSA Technical Report DOT HS 808 552. U.S. Department of Transportation. 57 p. Available from Internet: <http://isddc.dot.gov/ OLPFiles/NHTSA/006700.pdf>.

Sælensminde, K. 2001. Verdsetting av trafikksikkerhet $i$ ulike lands nytte-kostnadsanalyser [Valuation of road safety in various countries' cost-benefit analysis]. Arbeidsdokument [Working document] SM/1352/2001, Transportøkonomisk institutt [Insitute of Transport Economics], Oslo (in Norwegian).

Schwab Christe, N. G.; Soguel, N. C. 1995. Contingent Valuation, Transport Safety and the Value of Life. 1st edition. Springer. $208 \mathrm{p}$.

Social and Economic Consequences of Road Traffic Injury in Europe. 2007. European Transport Safety Council (ETSC). 48 p. Available from Internet: <http://www.etsc.eu/documents/Social\%20and\%20economic\%20 consequences $\% 20$ of\%20road\%20traffic\%20injury\%20in\%20Europe.pdf $>$.

Steimetz, S. S. C. 2008. Defensive driving and the external costs of accidents and travel delays, Transportation Research Part B: Methodological 42(9): 703-724. doi:10.1016/j.trb.2008.01.007

Valli, P.; Sarkar, P. K. 1997. Models for road accident in India, Highway Research Bulletin 56: 1-11. 